\title{
АНАЛИЗ ЗАРУБЕЖНЫХ И ОТЕЧЕСТВЕННЫХ РЕЙТИНГОВ УСТОЙЧИВОГО РАЗВИТИЯ (ЕSG) ВЕДУЩИХ НЕФТЕГАЗОВЫХ КОМПАНИЙ МИРА. ОЦЕНКА ВЛИЯНИЯ РЕЙТИНГА ЕSG НА КАПИТАЛИЗАЦИЮ КОМПАНИИ.
}

\author{
(c) 2021 Александров Виктор Викторович \\ студент магистратуры направление стратегический менеджмент в ТЭК, \\ Национальный исследовательский университет «Высшая школа экономики», Россия, Москва \\ направление «Финансовый менеджмент и рынок капиталов» \\ Финансовый университет при Правительстве РФ, Россия, Москва \\ E-mail: vvaleksandrov_1@edu.hse.ru,vvvpal15@yandex.ru
}

B работе были проанализированы современные актуальные поставщики рейтингов ESG отчетности компаний. Для анализа были выбраны ведущие нефтегазовые компании мира (мейджоры), которые являются наиболее заинтересованными в современной политике устойчивого развития, так как являются основными компаниями-эмитентами углекислого газа. Анализ ведущих рейтинговых агентств ESG показал отсутствие общей нормативно-правовой базы, общей методологии, унифицированной формы нефинансовой отчетности компаний, что в свою очередь усложняет процесс принятия решений институциональными и индивидуальными инвесторами при выборе объекта инвестиций. В данной работе сделаны выводы по пути развития методологии поставщиков рейтинговых агентств ESG отчётности. Составленная итоговая таблица рангов нефтегазовых компаний позволит актуализировать современные бенчмарки нефинансовой отчётности, а также выявляет компании-аутсайдеры отрасли. Также данное исследование на основе шести построенных эконометрических моделей показывает линейную зависимость, а также степень влияния ESG рейтинга нефтегазовых компаний на показатели капитализации.

Ключевые слова: устойчивое развитие, ESG-рейтинги, капитализация, нефтегазовые компании, нефинансовая отчётность, ESG-инвестиции.

\section{Введение}

За последнее десятилетие формы устойчивого финансирования значительно расширились из-за растущего спроса со стороны институциональных инвесторов и физических лиц, для лучшего отражения вопросов устойчивого развития в их инвестиционных решениях. В частности, использование экологических, социальных и управленческих инвестиционных подходов (ESG) было обусловлено возросшим спросом инвесторов на более эффективное использование нефинансовой информации отчетности для принятия решений о распределении активов для повышения долгосрочной доходности вложений, а также наилучшей структуры портфелей с учётом устойчивого развития. В этом отношении растущая обеспокоенность по поводу воздействия изменения климата и последствий пандемии привлекла повышенное внимание к экологическим и социальным рискам в сочетании с политическими сигналами о том, что финансовый сектор должен быть движущей силой в обеспечении глобальной устойчивости.
Раскрытие информации и рейтинги ESG представляют собой все более важный инструмент для интеграции аспектов устойчивого развития в инвестиционный процесс несколькими способами. Во-первых, практика ESG помогает инвесторам, которые стремятся оценить финансовую значимость нефинансовой отчетности об условиях, методах и стратегиях, связанных с экологическими, социальными и управленческими проблемами в среднесрочной перспективе. Например, они могут относиться к методам управления рисками для уменьшения воздействия изменения климата на результаты деятельности компании или к стратегиям использования возобновляемых источников энергии для новых возможностей роста компании. Во-вторых, рейтинги и показатели ESG также используются инвесторами для мониторинга и оценки воздействия своих инвестиций, например, для сокращения выбросов углерода или более строгого соблюдения стандартов в области прав человека. Кроме того, некоторые инвесторы могут использовать эти показатели для учета сочетания обо- 
их факторов в зависимости от своей инвестиционной стратегии и цели. Для каждой из этих целей критерии ESG предоставляют инвесторам полезную основу для оценки того, как эти важные нефинансовые факторы в краткосрочной перспективе могут повлиять на результаты деятельности компании и повлиять на ее развитие в долгосрочной перспективе. Таким образом, раскрытие информации, показателей ESG должно помогать инвесторам в принятии более обоснованных решений и оценочных суждений.

Важно отметить, что указанные аспекты не отменяют концептуальных преимуществ учета критериев ESG в инвестиционном процессе. Дополнительная информация, предоставляемая критериями ESG, предлагает дополнительные ценные данные о том, как менеджмент компании работает для поддержки долгосрочного инвестирования. Тем не менее, нынешние подходы к оценкам и рейтингам ESG при анализе методологий поставщиков рейтингов выявляют непоследовательность и несопоставимость и в дальнейшем рискуют снизить их потенциальную ценность. Хотя составление рейтингов ESG конструктивно по своей концепции и потенциально полезно для раскрытия ценной информации, необходимо решить ряд текущих проблем, прежде чем инвесторы смогут доверять целостности таких инструментов на финансовых рынках.

K рейтингам ESG и поставщикам индексов относятся фирмы, которые предоставляют оценку эмитентов акций и долговых обязательств на основе раскрытия их нефинансовой отчетности и отчетов устойчивого развития, которые прямо или косвенно предлагают показатели и информацию, определяющие рейтинги ESG. Некоторые из рейтингов на сегодняшний день являются по большей части количественными, с использованием и взвешиванием многочисленных показателей подкатегорий, основанных на определенных количественных данных, которые либо предлагаются корпоративными эмитентами, либо взяты из других источников, таких как различные СМИ, аналитические агентства. Рейтинговые компании предлагают ряд стилизованных эталонов, которые, в свою очередь, позволяют разрабатывать продукты фондов для пассивного или активного инвестирования, а также для использования управляющими портфелями в качестве эталона для сравнения их способности генерировать доходность с поправкой на риск. В связи с их растущим интересом в качестве эта- лонов для инвестирования в ESG, способ создания индексов, степень склонности к более высоким оценкам ESG и другие формы, такие как тематические индексы (например, эмитенты с высоким «S»), имеют большое влияние в руководстве общим управлением портфелем ESG.

Рейтинговые агентства пытаются сопоставить и измерить ключевые критерии, чтобы помочь эмитентам предоставлять инвесторам последовательные и релевантные рейтинги ESG.

Кроме того, регулирующие органы со всего мира все активнее участвуют в надзоре и понимании того, как создаются и измеряются показатели ESG, чтобы создать четкую основу для инвесторов.

В настоящее время происходит переход $\mathrm{K}$ финансированию устойчивого развития, и поэтому рейтинги ESG являются важным инструментом. В этом отношении анализ рейтингов ESG и связанных с ними результатов подчеркивает трудности, с которыми сталкиваются инвесторы, и то, насколько фундаментально эти рейтинги могут отличаться в зависимости от источника рейтинга. В основном это связано с методологическими различиями в структурировании рейтингов, а также с тем, как учитывается значимость того или иного показателя.

Подходы к оценке начинаются с рассмотрения и определения соответствующих критериев в рамках каждого из факторов E, S и G. Факторы окружающей среды могут включать использование природных ресурсов, выбросы углерода, энергоэффективность, загрязнение окружающей среды и инициативы в области устойчивого развития. Социальные факторы могут включать вопросы, связанные с персоналом (здоровье, разнообразие, обучение, гендерный состав), и более широкие социальные проблемы, такие как права человека, конфиденциальность данных и участие в сообществе. Факторы управления могут включать в себя корпоративное управление и корпоративное поведение, начиная от прав акционеров и заканчивая вознаграждениями руководителей.

Разные поставщики используют разные метрики и данные, по-разному агрегированные и переводимые для создания общих оценок ESG. Каждый создатель рейтинга оценивает различные аспекты устойчивости компаний, которые он анализирует. Затем эти данные и аспекты объединяются для создания оценки ключевого столпа, которая обычно определяет один из элементов, поддерживающих столпы (Е, S и G). 


\section{Аспекты развития ESG рейтингов}

По мере развития ESG-инвестирования появляется потенциал для эффективного сбора прогнозной информации по экологическим, социальным и корпоративным вопросам, что способствует принятию инвесторами решений о долгосрочных рисках и устойчивости финансовых результатов. Однако требуется дополнительная работа для обеспечения того, чтобы процессы раскрытия факторов ESG, рейтинга, инвестиций были последовательными, прозрачными и эффективными в следующих аспектах:

Преодоление предвзятого отношения к раскрытию информации для повышения справедливости оценок ESG эмитента. Многочисленные исследования и исследования OECD показывают, что существует смещение оценок ESG в пользу компаний с большой капитализацией в ущерб малых и средних предприятий. Это явление может несправедливо исказить информацию о компаниях-эмитентах МСП более высокой стоимостью капитала, а также может исказить результаты деятельности ESG по сравнению с традиционными портфелями, недооценивая динамику роста большинства более мелких фирм. Поскольку это может быть связано с тем, что текущие затраты на соответствующее раскрытие ESG могут быть восприняты как чрезмерные, по крайней мере, частью более мелких эмитентов, большая ясность и международная стандартизация раскрытия информации могут помочь снизить затраты на отчетность и стимулировать адекватное раскрытие ESG.

Обеспечение актуальности и ясности рамок отчетности для раскрытия ESG. Несмотря на достигнутый на сегодняшний день прогресс в отчетности по факторам ESG, все еще наблюдаются существенные недостатки в отношении последовательности, сопоставимости и качества, что подрывает ее полезность для инвесторов. Еще многое предстоит сделать для обеспечения того, чтобы эмитенты могли полагаться на основные критерии и показатели для раскрытия информации $\mathrm{E}, \mathrm{S}$ и $\mathrm{G}$, которые актуальны для широкого круга инвесторов в акции и долговые обязательства и поддерживаются фондовыми биржами и организациями по раскрытию информации. Унифицированный и принятый глобальный набор принципов и указаний для согласованной и содержательной отчетности в ESG поможет накопить масштабируемый опыт для эмитентов и улучшить согласованность, со- поставимость и надежность для инвесторов и аналитиков. Более того, в дальнейшем это позволит всем пользователям оценить значимость таких раскрытий с течением времени, чтобы их можно было дополнительно прояснить.

Повышение прозрачности и стандартизации основных элементов методологий рейтингов ESG для обеспечения широкого доступа инвесторов к метрикам и методологиям результатов рейтингов. Существенно различающиеся результаты у основных поставщиков рейтингов ESG - в отличие от показателей кредитных рейтингов - могут создать неопределенность на рынке среди институциональных инвесторов, управляющих фондами и неквалифицированных инвесторов относительно того, что представляет собой компания с высоким рейтингом ESG. Если не изменить подход к унификации рейтингов, то существующая субъективность в оценках, может подорвать доверие инвесторов к оценкам ESG, основным индексам ESG и портфелям, созданным на основе этих продуктов. Необходимо прояснить, как факторы и показатели подкатегорий E, S и G, их вес и субъективная оценка влияют на окончательные оценки ESG. Это позволит пользователям и эмитентам понять и сравнить методологии и результаты. Такая прозрачность особенно оправдана, если оценки рейтинговых агентств по-прежнему сильно различаются.

Усиление связи между рейтингами ESG и финансовой составляющей в среднесрочной и долгосрочной перспективе. Пока существуют неоднозначные свидетельства того, что перспективы инвестирования в ESG будут соответствовать или превзойдут показатели традиционных инвестиционных индексов, что говорит о том, что преимущества раскрытия информации ESG для получения перспективной информации, которая является финансово существенной, все еще находится на ранней стадии разработки. Таким образом, возникает необходимость в более тщательной оценке того, как финансовая составляющая отражена и будет в дальнейшем отражена в рейтингах, тестах и портфелях ESG.

Обеспечить надлежащее обозначение и раскрытие информации о продуктах ESG, чтобы гарантировать, что их слабые места, риски и другие характеристики достаточно существенны, сопоставимы и согласованы, чтобы позволить инвесторам принимать ин- 
вестиционные решения и выбирать в соответствии с их инвестиционными целями и устойчивостью к риску. Таким образом, очень важна четкость, с которой продукты ESG в разных рейтингах, тестах и фондах четко разграничивают финансовые и социальные аспекты инвестирования в ESG. В частности, если функции продукта предназначены для согласования с социальным инвестированием, а не с финансовой отдачей, такой выбор должен быть предельно ясен для инвесторов. Точно так же, когда фонды демонстрируют положительную согласованность с экологическими проблемами, необходимо четко указать подверженность углеродоемким (в частности, нефтегазодобывающим) отраслям и обоснование этой подверженности.

Укрепление нормативно-правовой базы важный шаг к поддержанию последовательности и устойчивости на основных рынках поставщиков рейтинга ESG. Стоит отметить, что необходимо более активное взаимодействие между финансовой отраслью и государственным сектором для укрепления опыта, касающихся защиты инвесторов и целостности рынка, связанных с раскрытием информации, данными, рейтингами, индексами и инвестиционными механизмами. Несомненно, регулирующие органы некоторых развитых стран с лучшими финансовыми рынками уже занимаются этими вопросами и добиваются хороших результатов. Однако рынки капитала и устойчивое финансирование имеют глобальный охват, как и социальный аспект, которые они стремятся оценить. Следовательно, могут потребоваться глобальные всеобщие принципы, которые помогут установить эталонные практики (бенчмарки), учитывающие региональные и национальные различия, обеспечивая при этом конструктивный уровень согласованности, прозрачности и доверия. Таким образом, чтобы раскрыть потенциальные преимущества инвестирования в ESG для долгосрочного устойчивого финансирования, необходимо больше уделять внимания и прилагать усилий для повышения прозрачности, международной согласованности, соответствия значимости и ясности в стратегиях инвестфондов, поскольку они связаны с устойчивым финансированием. Это поможет укрепить прозрачность, уверенность и целостность устойчивого финансирования на глобальных финансовых рынках, что будет способствовать устойчивому развитию и всеобщему экономическому росту.
Чтобы удовлетворить растущий спрос на устойчивые финансовые продукты для поддержки перехода к низкоуглеродной экономике, поставщики рейтингов ESG и инвестиционные фонды стремятся интегрировать показатели, связанные с экологической устойчивостью, смягчением климатических рисков и стратегиями в отношении возобновляемых источников энергии.

\section{Итоговый результат ранжирования рей- тингов ESG}

B работе были изучены и проанализированы методики и методы расчёта рейтингов ESG, которые на сегодняшний день были наиболее актуальны и значимы для компаний, предоставляющих нефинансовую отчетность по устойчивому развитию компаний. В результате анализа были выявлены общие тренды и существенные различия в методологиях присвоения рейтинга ESG компаний.

В процессе выполнения работы были проанализированы рейтинги таких компаний и агентств как MSCI, Sustainalytics, SIP Global, CDP (Carbon Disclosure Project), рейтинговое агентство AK\&M, Рейтинг World Benchmarking Alliance (WBA), CSR Hub, Expert RA (Россия), Expert RA (Europe), Рейтинг открытости экологической информации нефтегазовых компаний.

Для составления итоговых результатов ранжирования рейтингов ESG для 12 нефтегазовых компаниЙ (ПАО Лукойл, ПАО Газпром, ПАО Роснефть, ПАО Новатек, Eni, BP, Equinor, Shell, Exxon Mobil, Chevron, Sinopec, TOTALEnergie), была составлена таблица, где компании на основе своих рейтингов были сгруппированы в 5 подгрупп, согласно тем баллам, индексам, оценкам, местам, которые они получили от рейтинговых агентств. Для каждой компании было определено место в 6 основных рейтинговых поставщиков ESG. В дальнейшем для каждой компании был определен набор занимаемых мест в каждом рейтинге. Согласно этому набору мест определялась итоговая позиция, в соответствии с методикой, где ранжирование происходило с 1 по 12 место (в итоге мест 11, так как для компании ВР недостаточно данных). Способ состоял в отборе количества раз, которые компания занимала те или иные места в рассматриваемых рейтингах. Соответственно, чем чаще компания занимала места выше в рейтингах, тем выше будет её итоговое место в ранге. Например, компания 


\begin{tabular}{|c|c|c|c|c|c|c|c|c|c|c|c|}
\hline & MSCI & $\begin{array}{l}\text { Sustainalytic } \\
\mathrm{s}\end{array}$ & SIP Global & $\begin{array}{l}\text { Рейтинг } \\
\text { CDP }\end{array}$ & CSR Hub & $\begin{array}{l}\text { World } \\
\text { Benchmarking } \\
\text { Alliance }\end{array}$ & PA AK\&M & Expert RA & $\begin{array}{l}\text { Рейтинг } \\
\text { открытости } \\
\text { экологической } \\
\text { информации } \\
\text { нефтегазовых } \\
\text { компаний }\end{array}$ & $\begin{array}{l}\text { Ранжирование } \\
\text { по занятым } \\
\text { местам }\end{array}$ & $\begin{array}{l}\text { Итоговое } \\
\text { место }\end{array}$ \\
\hline Газпром & BB & 69/248 & $42 / 100$ & B/B- & $66 / 100$ & $\begin{array}{l}\text { АСТ 2,3 и Е- } \\
47 \text { из } 100\end{array}$ & 92/Resg1 & 16 & 8 & $\begin{array}{c}1 \text { (место 4-5) } \\
2 \text { (место 6-8) } \\
2 \text { (место 9-11) } \\
1 \text { (место 12) }\end{array}$ & 8 \\
\hline ENI & A & $8 / 248$ & $47 / 100$ & $\mathrm{~A}-/ \mathrm{A}-$ & $94 / 100$ & $\begin{array}{l}\text { АСТ } 7.3 \mathrm{C}=. \\
4 \text { из } 100\end{array}$ & & & & $\begin{array}{l}4 \text { (место 1-3) } \\
2 \text { (место 4-5) }\end{array}$ & $\angle$ \\
\hline $\begin{array}{l}\text { EQUINOR } \\
\text { ASA }\end{array}$ & AAA & 29/248 & $45 / 100$ & $\mathrm{~B} / \mathrm{F}$ & $88 / 100$ & $\begin{array}{l}\text { АСТ } 4.9 \mathrm{C}= \\
8 \text { из } 100\end{array}$ & & & & $\begin{array}{l}3 \text { (место 1-3) } \\
1 \text { (место 4-5) } \\
2 \text { (место 6-8) }\end{array}$ & 3 \\
\hline Shell & A & $67 / 248$ & $68 / 100$ & $\mathrm{~B} / \mathrm{F}$ & $70 / 100$ & $\begin{array}{l}\text { АСТ } 3.4 \mathrm{C}= \\
10 \text { из } 100\end{array}$ & & & & $\begin{array}{l}1 \text { (место 1-3) } \\
2 \text { (место 4-5) } \\
2 \text { ( место 6-8) } \\
1 \text { (место 9-11) }\end{array}$ & 4 \\
\hline Lukoil & BBB & $53 / 248$ & $46 / 100$ & $\mathrm{C} / \mathrm{F}$ & $76 / 100$ & $\begin{array}{l}\text { АСТ 2.1E- } \\
53 \text { из } 100\end{array}$ & 82,4/ Resg1 & 3 & 3 & $\begin{array}{l}2 \text { (место 4-5) } \\
2 \text { ( место 6-8) } \\
2 \text { ( место 9-11) }\end{array}$ & \\
\hline $\begin{array}{l}\text { Exxon } \\
\text { Mobil }\end{array}$ & ----- & $61 / 248$ & $36 / 100$ & $\mathrm{~F} / \mathrm{F}$ & $71 / 100$ & $\begin{array}{l}\text { АСТ } 2.2 \mathrm{E}- \\
49 \text { из } 100\end{array}$ & & & & $\begin{array}{l}2 \text { ( место 6-8) } \\
2 \text { ( место 9-11) } \\
1 \text { ( место 12) }\end{array}$ & \\
\hline Total & A & $12 / 248$ & $72 / 100$ & A-/F- & $95 / 100$ & $\begin{array}{l}\text { ACT } 6.1 \quad C= \\
6 / 100\end{array}$ & & & & $\begin{array}{l}5 \text { ( место 1-3) } \\
1 \text { (место 4-5) }\end{array}$ & \\
\hline Chevron & BBB & $102 / 248$ & $44 / 100$ & $\mathrm{~F} / \mathrm{F}$ & $81 / 100$ & $\begin{array}{l}\text { АСТ } 2,7 \mathrm{E}- \\
45 \text { из } 100\end{array}$ & & & & $\begin{array}{c}1 \text { (место 4-5) } \\
3 \text { (место 6-8) } \\
1 \text { (место 9-11) } \\
1 \text { (место 12) }\end{array}$ & \\
\hline Sinopec & B & $190 / 248$ & $31 / 100$ & ----- & $74 / 100$ & $\begin{array}{l}\text { АСТ 2.0E- } \\
54 \text { из } 100\end{array}$ & & & & $\begin{array}{l}2 \text { (место9-11) } \\
3 \text { (место 12) }\end{array}$ & \\
\hline Rosneft & BB & $44 / 248$ & $44 / 100$ & $\mathrm{C} / \mathrm{B}-$ & $82 / 100$ & $\begin{array}{l}\text { АСТ 1,5E- } \\
61 \text { из } 100\end{array}$ & 86,8/Resg 1 & 17 & 9 & $\begin{array}{c}2 \text { (место 4-5) } \\
1 \text { (место 6-8) } \\
3 \text { (место 9-11) }\end{array}$ & \\
\hline $\begin{array}{l}\text { British } \\
\text { Petroleum }\end{array}$ & ----- & ----- & ------- & --נ-10 & $77 / 100$ & ------ & & & & ----------- & \\
\hline Novatek & $\begin{array}{l}\text { не отнесена } \\
\text { к ВИНК }\end{array}$ & $46 / 248$ & $40 / 100$ & --- & $75 / 100$ & $\begin{array}{l}\text { АСТ 1.1E- } \\
72 \text { из } 100\end{array}$ & 66,8/ Resg2 & 31 & 12 & $\begin{array}{c}1 \text { (место 4-5) } \\
1 \text { (место 6-8) } \\
1 \text { ( место 9-11) } \\
1 \text { ( место 12) }\end{array}$ & 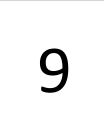 \\
\hline
\end{tabular}

\begin{tabular}{|l|l|}
\hline Легенда & \\
\hline & 1-3 места \\
\hline $4-5$ места \\
\hline 6-8 места \\
\hline $9-11$ места \\
\hline 12 место \\
\hline
\end{tabular}

Рисунок 1. Итоговая таблица ранжирования рейтингов ESG (составлена автором) 
TOTAL больше всех заняла места с 1 по 3 (5 раз), соответственно в итоговом ранге компании присвоено 1 место. Если у компаний в процессе ранжирования одинаковое количество занятых мест по разбитым подгруппам (с 1 по 3, с 4 по 5, с 6 по 8, с 9 по 11, и 12 места), то в расчёт берется следующая подгруппа мест, например у компаний Лукойл и Роснефть одинаковое количество набранных мест с 4 по 5, по 2 раза, соответственно рассматривается следующая подгруппа мест с 6 по 8, где компания ПАО Лукойл встречалась чаще в рейтингах- 2 раза, а компания Роснефть 1 раз, а в подгруппе мест с 9 по 11 Роснефть встречалась 3 раза, а Лукойл 2 раза, что позволяет определить ПАО Лукойл на итоговое 5 место в табеле о рангах а ПАО Роснефть на 6.

\section{Влияние рейтинга ESG на капитализа- цию нефтегазовых компаний мира}

На сегодняшний день существует много эмпирических исследований, где исследователи анализируют влияние социальной ответственности бизнеса на рыночную капитализацию. ESG Score, рассчитанный компанией Bloomberg, показывает уровень раскрытия информации по факторам ESG, а именно, что компания делает и какие практики использует по окружающей среде, социальной ответственности и корпоративному управлению. Чем выше показатель, тем больше информации компания раскрывает по факторам ESG, таким образом, если показатель равняется 0 , то компания не предоставляет никакой информации по факторам ESG, а если показатель равняется 100, то компания раскрывает максимальную информацию о том, как она взаимодействует со своими ключевыми стейкхолдерами.

Было построено 6 моделей для проверки гипотезы

В первой модели были проанализированы данные 14 компаний нефтегазового сектоpa (ПАО ЛукоЙЛ, ПАО ГазПром, ПАО Роснефть, Petrochina, Petrobras, ПАО Газпромнефть, ПАО Газпромнефть, Eni, BP, Equinor, Shell, Exxon Mobil, Chevron, Sinopec, TOTAL Energie с 2007 года по 2020 год включительно. В итоге получилось 195 наблюдений. Показатель корреляции составил 0,37, что свидетельствует о слабой взаимосвязи показателей капитализации выбранных компаний и рейтинга ESG. Дальнейшее построение и анализ регрессионной статистики показало, что коэффициент $\mathrm{b}$ оказался статистически незначим, следовательно есть основание считать, что значение капитализации компании не зависит от уровня рейтинга ESG для данной модели. Проверка дисперсионного анализа регрессии (F - критерий Фишера) также показала отсутствие линейная связь между переменными.

\begin{tabular}{|c|c|c|c|c|c|c|c|c|c|}
\hline вЫвод итогов & & & & & & & & & \\
\hline \multicolumn{10}{|c|}{ Все компании все года } \\
\hline \multicolumn{10}{|c|}{ Регрессионная статистика } \\
\hline Множественный R & 0,039127777 & & & & & & & & \\
\hline R-квадрат & 0,001530983 & & & & & & & & \\
\hline Нормированный R- & $-0,003642432$ & & & & & & & & \\
\hline Стандартная ошиб & 107,5734553 & & & & & & & & \\
\hline Наблюдения & 195 & & & & & & & & \\
\hline Корреляция & $-0,037208599$ & & & & & & & & \\
\hline \multicolumn{10}{|c|}{ Дисперсионный анализ } \\
\hline & $d f$ & SS & MS & $F$ & Значимость $F$ & & & & \\
\hline Регрессия & 1 & 3424,54842 & 3424,548422 & 0,29593278 & 0,587071389 & F критич & 3,89009224 & $>$ & F наблюд \\
\hline Остаток & 193 & 2233405,32 & 11572,04828 & & & \multirow{2}{*}{\multicolumn{4}{|c|}{$\begin{array}{c}\text { следовательно между переменными отсутствует линейная } \\
\text { связь }\end{array}$}} \\
\hline \multirow[t]{2}{*}{ Итого } & 194 & 2236829,87 & & & & & & & \\
\hline & Коэфффициенты & дартная ош & u t-статистика & Р-значение & Нижние 95\% & \multicolumn{3}{|c|}{ Верхние 95\% 1ижние 95,0\%ерхние 95,0\% } & \\
\hline Y-пересечение & 138,5395435 & 30,4190879 & 4,554362185 & $9,29548 \mathrm{E}-06$ & 78,54301294 & 198,536074 & 78,5430129 & 198,536074 & \\
\hline \multirow[t]{4}{*}{56,85} & $-0,307505468$ & 0,56527048 & $-0,543997041$ & 0,587071389 & $-1,422406338$ & 0,807395403 & $-1,4224063$ & 0,8073954 & \\
\hline & & & t критич & 1,972331676 & & t критич b & 1,97233168 & & \\
\hline & & & t статистич а & 4,554362185 & & t статистич b & 0,54399704 & & \\
\hline & & & t статистич а & $>$ & t критич & t статистич b & $<$ & t критич b & \\
\hline ВЫВОД ОСТАТКА & & & \multicolumn{3}{|c|}{ Коэффициент а статистически значим } & \multicolumn{3}{|c|}{ Коэффициент b статистически не значим } & \\
\hline
\end{tabular}

Рисунок 2. Регрессионный анализ ESG рейтинга нефтегазовых компаний и капитализации (модель 1) 
В модели 2 данного исследования была проанализирована взаимосвязь 56 из 195 значений капитализации компаний и рейтинга ESG. Степень корреляции оказалась слабой $-0,35$. Как и в первой модели коэффициент $\mathrm{b}$ данной модели регрессии оказался после проверки статистически незначим, а вот проверку дисперсионного анализа по Фишеру модель прошла. Но незначительный показатели коэффициента детерминации- 0,13 и корреляции 0,35 , а также доказанная статистическая незначимость коэффициента $\mathrm{b}$ позволяет сделать вывод о том, что дальнейший анализ модели можно не продолжать.

Модель 3 показала лучшие результаты для проверки гипотезы. Была выбрана компания ВР и показатели с 2007 по 2020 годы включительно. Коэффициенты a и $\mathrm{b}$ прошли проверку на статистическую значимость, анализ критерия Фишера также оказался удачным, что позволило сделать вывод о существовании линейной связи между показателями капитализации компании и рейтингом ESG. Корреляция составила $-0,76$, что значительно выше показателей прошлых моделей. Регрессионный анализ показал умеренную связь рассматриваемых значений капитализации и рейтинга ESG. Дальнейшая проверка коэффициента корреляции показала его статистическую значимость с вероятностью 95\%.
Дальнейший анализ модели 3 на показатель средней ошибки аппроксимации выявил существенное превышение средних показателей ошибки (7-10) - 25,89. Следовательно, полученное значение позволяет сделать вывод о низком качестве данных, взятой для этой модели. Коэффициент корреляции, полученный по методу Спирмена - 0,61, указывает на относительно незначительное различие от коэффициента корреляции по методу Пирсона $(0,76)$. Проведенный анализ модели 3 позволяет с некоторыми ограничениями (значение ошибки аппроксимации), сделать вывод о том, что изменение капитализации компании ВР в 2007-2020 гг. на 32\% объясняется показателем ESG (Bloomberg score), что в свою очередь позволяет сказать, что 68\% изменения показателя капитализации компании приходится на другие факторы неучтенные в модели.

Модель 4 данного исследования, где анализировались показатели 2018 года по всем компаниям, изначально не прошла проверку по статистической значимости коэффициентов, следовательно не продолжался ее дальнейший анализ.

Модель 5 дублировала и тем самым должна была подтвердить модель 3. Были взяты также как и в модели 3 данные одной компании за

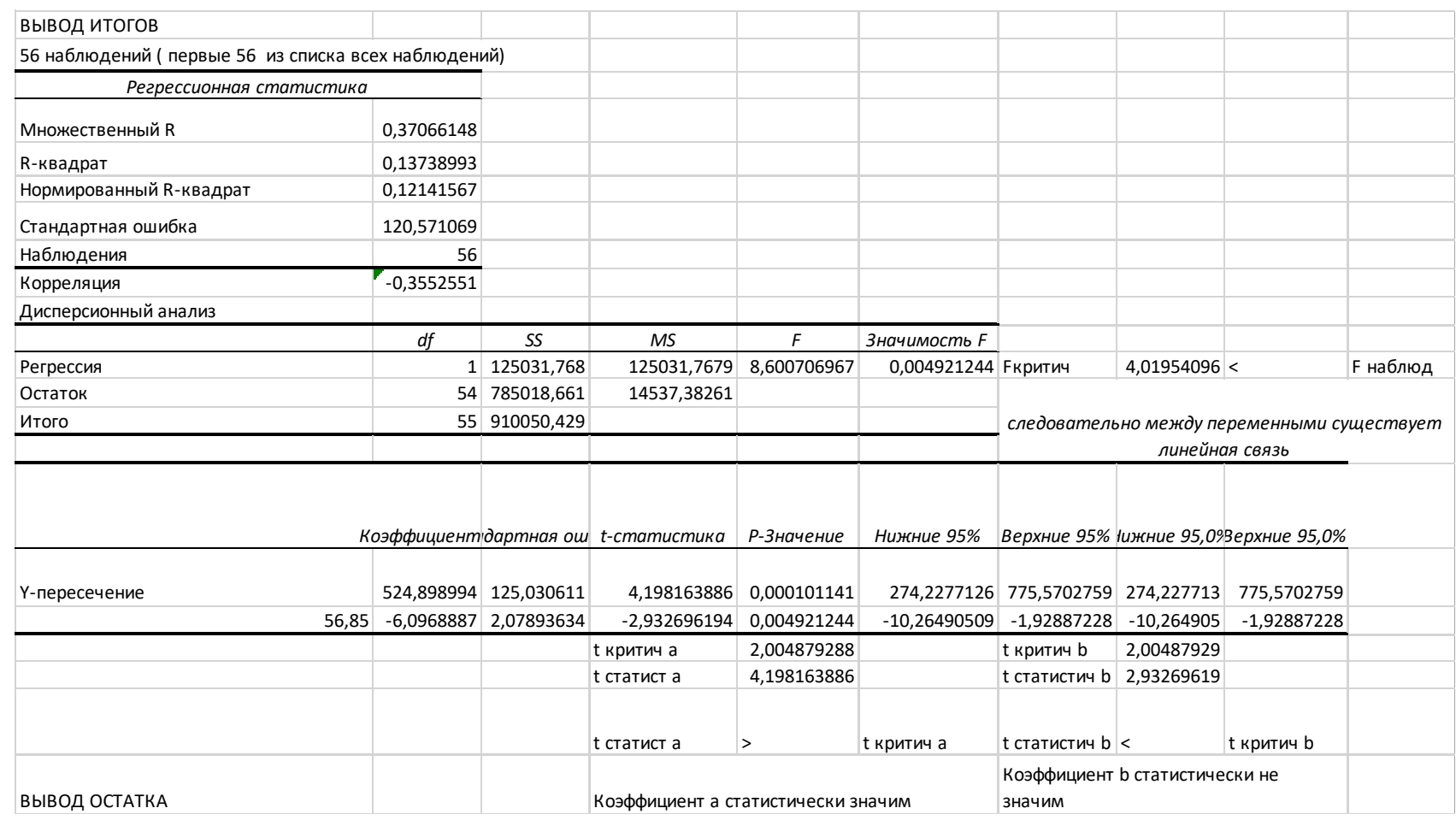

Рисунок 3. Регрессионный анализ ESG рейтинга нефтегазовых компаний и капитализации (модель 2) 


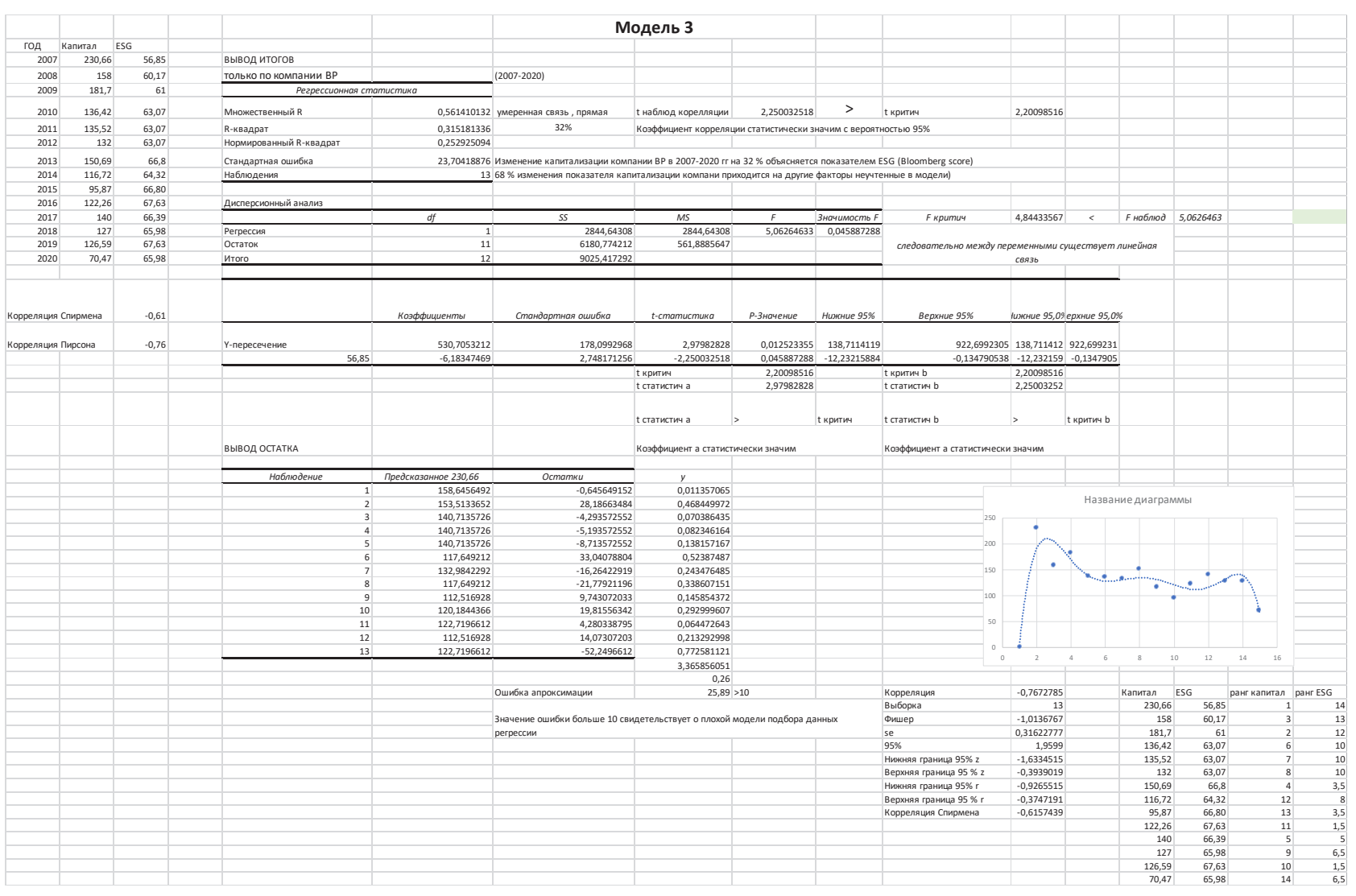

Рисунок 4. Регрессионный анализ ESG рейтинга нефтегазовых компаний и капитализации (модель 3)

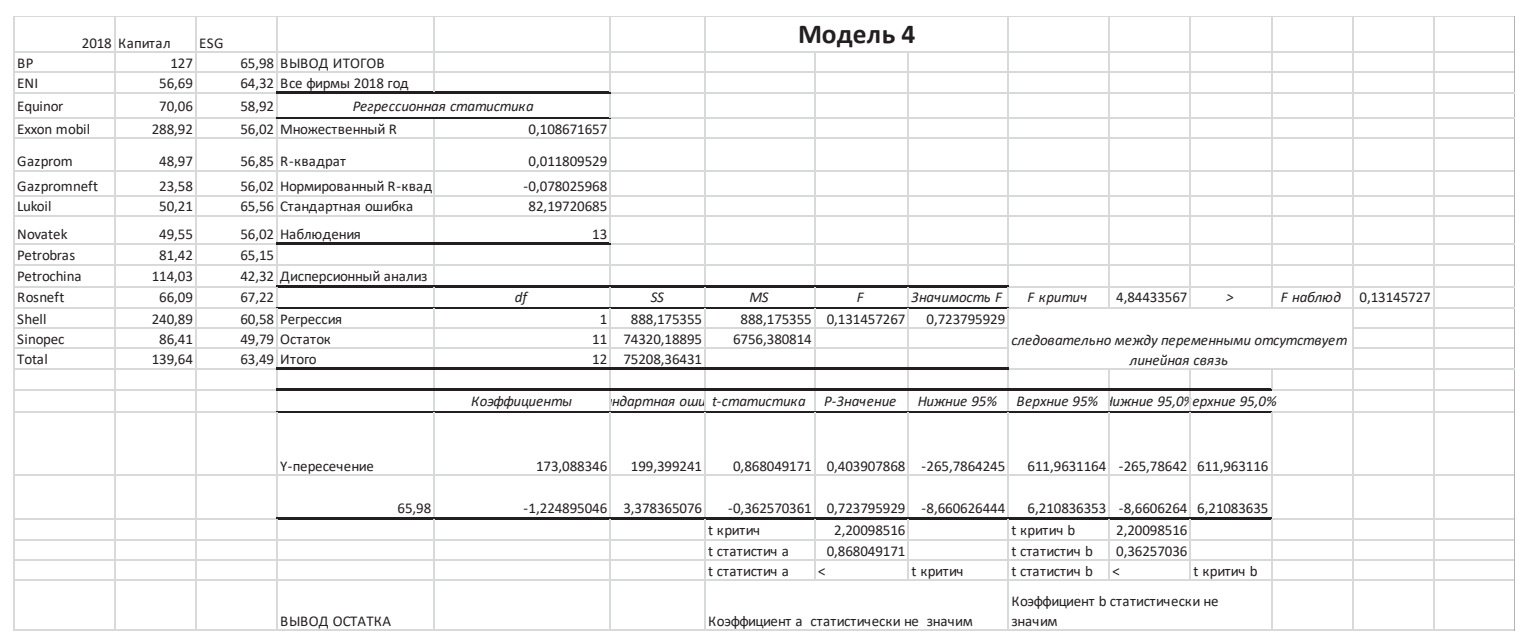

Рисунок 5. Регрессионный анализ ESG рейтинга нефтегазовых компаний и капитализации (модель 4) 
период 2007-2020, компании Газпромнефть. Но коэффициент корреляции значительно ниже, чем в модели «3»-0,2. Проверка не подтвердила статистическую значимость коэффициентов а и b. Полученное сравнение моделей 3 и 5 может свидетельствовать о более объективной оценке показателей ESG компании BP по сравнению с компанией Газпромнефть, особенно в периоде 2007-2011 годов.

\section{Заключение}

Несмотря на растущий интерес к факторам ESG, интеграция ESG по-прежнему является сложной задачей для многих инвесторов. Влияние факторов ESG на финансовые показатели инвестиций неясно, и ресурсы, необходимые для принятия обоснованных решений, остаются высокими. Надежные данные ESG еще не получили широкого доступа, что может помешать институциональным инвесторам оценить и проанализировать факторы и возможности ESG.

Внешние поставщики данных являются важным элементом процесса интеграции ESG для институциональных инвесторов. Существует широкий спектр соображений ESG, которые тре- буют специализированного анализа данных и могут побудить институциональных инвесторов полагаться, по крайней мере в некоторой степени, на внешних поставщиков данных и рейтинговые индексы, и агентства ESG. Использование внешних поставщиков услуг ESG может способствовать снижению затрат на анализ ESG и усилению влияния институциональных инвесторов на корпоративное и рыночное поведение. Однако использование внешних частных поставщиков также может привести к тому, что ESG станет упражнением для институциональных инвесторов или к тому, что они будут в значительной степени полагаться на данные и модели, которые не являются прозрачными.

Для дальнейшей более качественной и объективной оценки степени взаимосвязи показателей капитализации компаний нефтегазового сектора и показателей рейтинга ESG, следует изучить рейтинги ESG других компаний поставщиков и сравнить их с другими показателями инвестиционной деятельности и привлекательности компаний, такими, как например P/E price to earnings, $\mathrm{P} / \mathrm{S}$ price to sales, ROE return on common equity и другие.

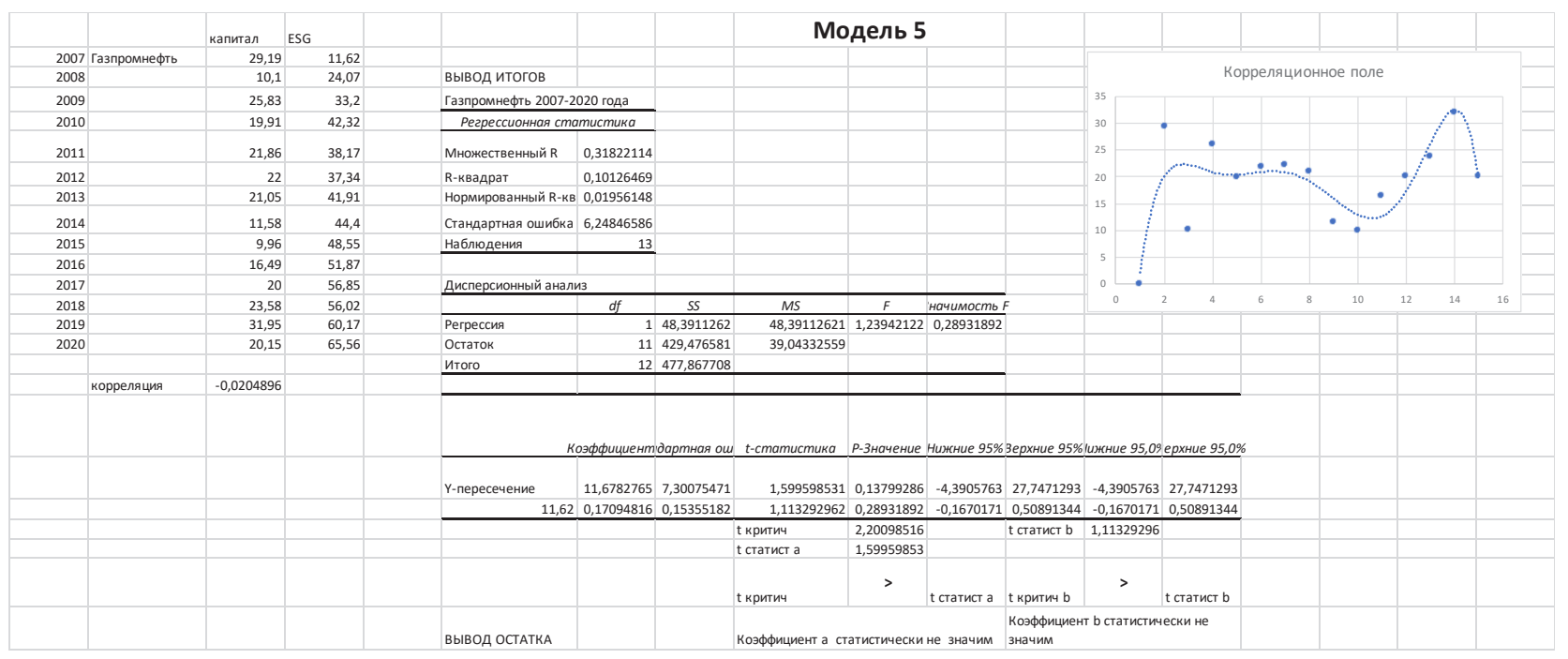

Рисунок 6. Регрессионный анализ ESG рейтинга нефтегазовых компаний и капитализации (модель 5) 


\section{Библиографический список}

1. Whelan T., Atz U., Clark C. ESG and financial performance: Uncovering the relationship by aggregating evidence from 1,000 plus studies published between 2015-2020. New York: NYU STERN Center for sustainable business; 2021. 19 p. URL: https://www.stern.nyu.edu/sites/default/files/assets/documents/ NYU-RAM_ESG-Paper_2021. pdf

2. Van Burren E., Plantinga A., Scholtens B. ESG integration and the investment management process: Fundamental investing reinvented. Journal of Business Ethics. 2016;138(3):525-533. DOI: 10.1007/s10551-015-2610-8

3. Ефимова О.В., Волков М. А., Королёва Д. А. Анализ влияния принципов EsG на доходность активов: эмпирическое исследование. Финансы: теория и практика. 2021;25(4):82-97. DOI: 10.26794/2587-5671-2021-25-482-97

4. Melas D., Nagy Z., Kulkarni P. Factor investing and ESG integration. In: Jurczenko E., ed. Factor investing: From traditional to alternative risk premia. Amsterdam: Elsevier; 2017:389-413.

5. Clark, Gordon L. and Feiner, Andreas and Viehs, Michael, From the Stockholder to the Stakeholder: How Sustainability Can Drive Financial Outperformance (March 5, 2015). Available SSRN: https://ssrn.com/abstract=2508281 or http://dx.doi.org/10.2139/ssrn.2508281

6. Саррисci M. The ESG integration paradox. Journal of Applied Corporate Finance. 2018;30(2):22-28. DOI: 10.1111/ jacf.12296

7. Visconti R. M. DCF metrics and the cost of capital: ESG drivers and sustainability patterns. 2021. URL: https://www. researchgate.net/publication/344953641

8. https://bba.bloomberg.net/?utm_source=bloomberg-menu\&utm_medium=terminal This document is being provided for the exclusive use of VIKTOR ALEKSANDROV at FINANCIAL UNI UNDER GOV OF RUSSIA.

9. OECD Business and Finance Outlook 2020// https://doi.org/10.1787/eb61fd29-en 